\title{
Haptoglobin treatment prevents cell-free hemoglobin exacerbated mortality in experimental rat sepsis
}

\author{
Christian A. Schaer ${ }^{1,2}$, Victor Jeger ${ }^{1,2}$, Thomas Gentinetta ${ }^{3}$, Donat R. Spahn², Florence Vallelian, \\ Alain Rudiger ${ }^{4}$ and Dominik J. Schaer ${ }^{1 *}$ (D)
}

*Correspondence:
dominik.schaer@usz.ch
${ }^{1}$ Division of Internal
Medicine, University
and University Hospital
Zurich, Raemistrasse 100,
8091 Zurich, Switzerland
Full list of author information
is available at the end of the
article

*Correspondence: dominik.schaer@usz.ch

Division of Internal and University Hospital Zurich, Raemistrasse 100 Full list of author information article
Sepsis is a dysregulated host response to infection leading to organ dysfunction, organ failure, and death. Multiple mechanisms promote hemolysis during sepsis, such as complement activation, disseminated intravascular coagulation, hemolytic pathogens, sepsis-induced erythrocyte dysfunction, blood transfusion, and medical procedures with extracorporeal circulation (e.g., renal replacement therapy) [1]. Clinical observations suggested that hemolysis with increased cell-free hemoglobin $(\mathrm{CFHb})$ in plasma correlated with reduced survival in sepsis patients [2-4]. CFHb is a toxin, which may worsen sepsis pathophysiology by nitric oxide depletion, oxidative tissue injury, activation of coagulation and innate immune pathways, and as an iron source for pathogens [5]. The acute phase protein haptoglobin is the archetypical $\mathrm{Hb}$ scavenger in plasma and irreversibly neutralizes the toxicity of bound $\mathrm{Hb}[1]$.

Here, we performed a prospective, randomized, blinded animal study to provide direct experimental evidence that $\mathrm{CFHb}$ exacerbates sepsis mortality and test whether haptoglobin administration could revert this potentially detrimental adverse effect of hemolysis. For this, we used a fluid resuscitated fecal peritonitis model in awake rats that we have characterized in detail earlier (Fig. 1a) [6]. We first validated an $\mathrm{Hb}$-administration protocol in 36 septic rats randomized to saline, $\mathrm{CFHb}$, or $\mathrm{Hb}$-haptoglobin infusion. Three hours after a bolus followed by continuous infusion, the mean total $\mathrm{Hb}$ concentrations in plasma were $5.4 \mu \mathrm{M}(\mathrm{SD} \pm 3.2 \mu \mathrm{M})$ in the saline group and $30.4 \mu \mathrm{M}(\mathrm{SD} \pm 17.3 \mu \mathrm{M})$ in the Hb group (Fig. 1b). These data confirmed that our infusion protocol resulted in plasma concentrations within the range of CFHb observed in patients with severe sepsis [2, 4]. Co-administration of human plasma-derived haptoglobin prevented Hb's renal clearance, resulting in higher concentrations than in the CFHb group $(54.7 \mu \mathrm{M} \pm 63.0 \mu \mathrm{M})$. We determined the fractions of $\mathrm{CFHb}, \mathrm{Hb}$-haptoglobin complexes, and heme-protein adducts by sizeexclusion chromatography. $\mathrm{CFHb}$ and heme-protein adducts eluting in the albumin region remained suppressed when haptoglobin was administered concomitantly with $\mathrm{CFHb}$. This confirms that $\mathrm{Hb}$ remains stabilized in the $\mathrm{Hb}$-haptoglobin complex for author(s) and the source, provide a link to the Creative Commons licence, and indicate if changes were made. The images or other third party material in this article are included in the article's Creative Commons licence, unless indicated otherwise in a credit line to the material. If material is not included in the article's Creative Commons licence and your intended use is not permitted by statutory regulation or exceeds the permitted use, you will need to obtain permission directly from the copyright holder. To view a copy of this licence, visit http:// creativecommons.org/licenses/by/4.0/. 


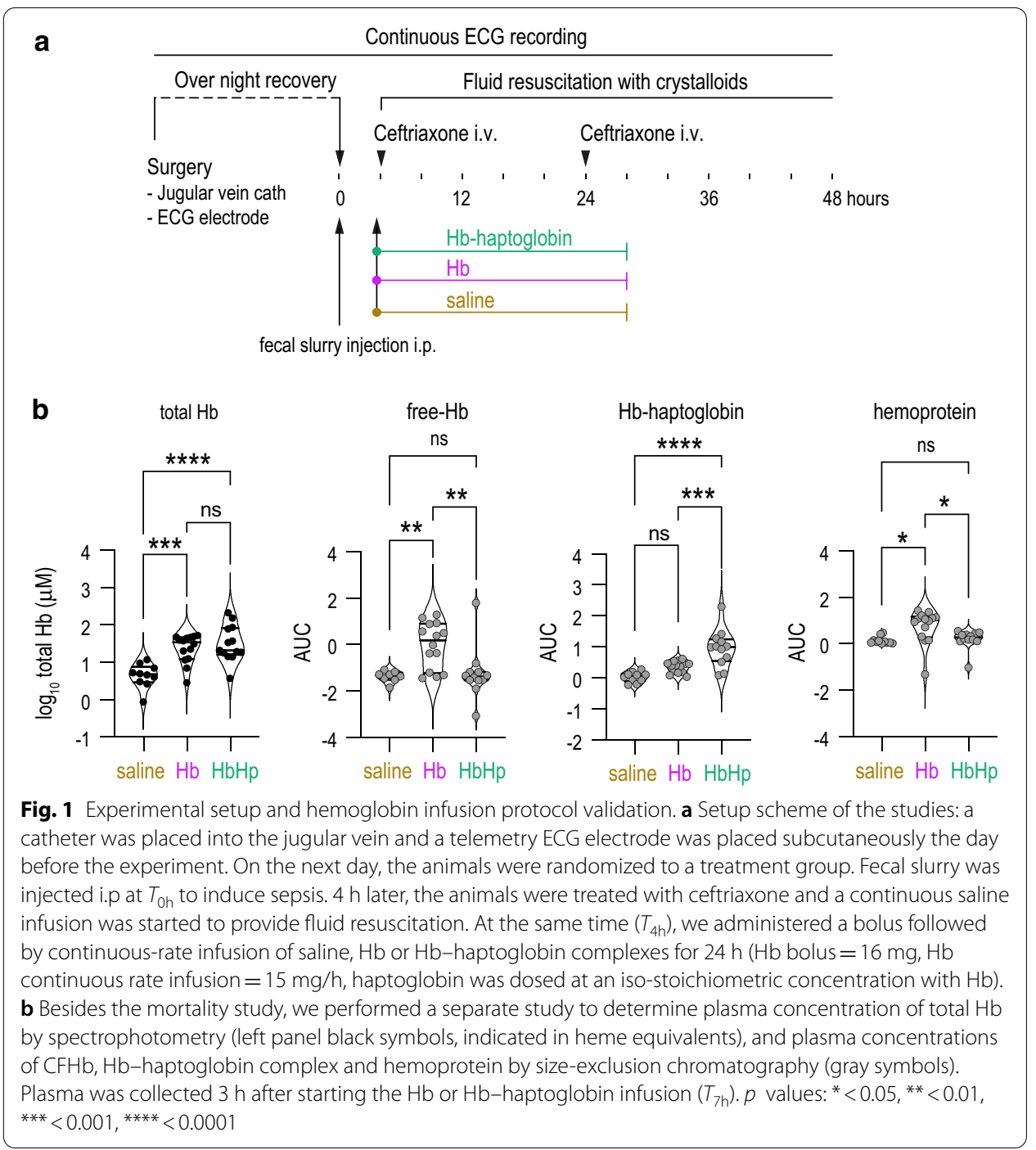

prolonged periods in circulation and that the complex efficiently prevents Hb degradation and heme release from $\mathrm{CFHb}[7,8]$.

In the main study, we randomized 54 septic Wistar rats to treatment with saline, $\mathrm{CFHb}$, or $\mathrm{Hb}$-haptoglobin. One animal randomized to the saline group had to be excluded from the study, because the intravenous catheter was dislocated during the experiment. In addition, five non-septic animals were infused with CFHb to exclude acute $\mathrm{Hb}$ toxicity in healthy animals. After fecal slurry injection, tachycardia developed in all treatment groups consistent with a systemic inflammatory response (i.e., sepsis) (Fig. 2a). The exact timepoint of animal death was determined based on ECG telemetry recordings. The survival data provided evidence for a significantly higher mortality in the group of septic rats infused with CFHb compared to the septic animals infused with only saline (61\% versus $12 \% ; p=0.0066)$. Co-administration of haptoglobin with $\mathrm{CFHb}$ improved mortality to $17 \%$, which was not significantly different from the saline infusion group (12\%) (Fig. 2b). 


\section{a}
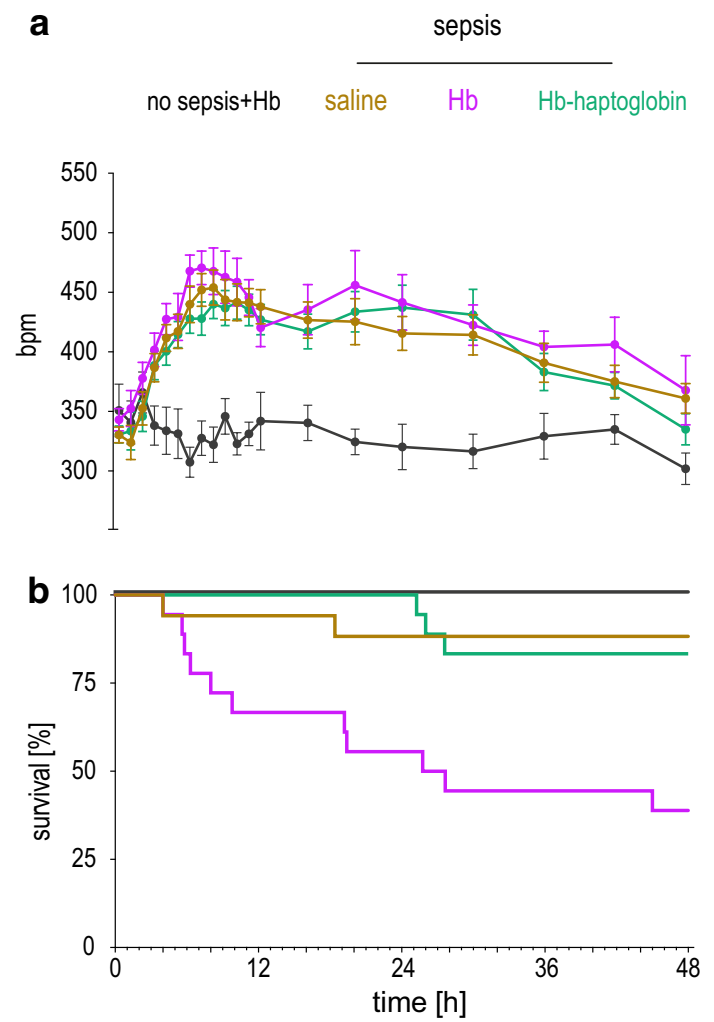

C

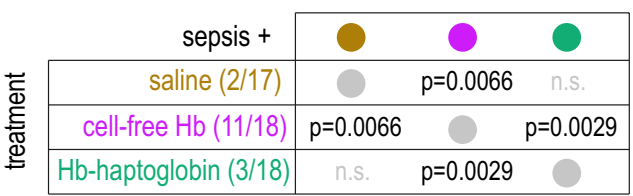

Fig. 2 Mortality studies in septic rats. Septic rats were randomized to treatment with a bolus followed by a continuous infusion of saline, $\mathrm{Hb}$, or $\mathrm{Hb}$-haptoglobin over $24 \mathrm{~h}$. All investigators were blinded for the treatment group. An additional group of non-septic rats was infused with $\mathrm{Hb}$ to exclude toxicity in healthy animals. a Heart rate recordings (mean \pm S.E.M) during the $48 \mathrm{~h}$ experiments. b Kaplan-Meier survival curves. Results of the statistical analysis are provided in the table (c). Survival proportions (Kaplan-Meier) were compared using a two-tailed Gehan-Breslow-Wilcoxon test. The familywise significance level of 0.05 was divided by the number of all possible comparisons $(n=6)$, resulting in a Bonferroni-corrected multiple-comparison significance level of 0.00833. [GraphPad Prism software version 8.0 (GraphPad Software, San Diego, CA, USA)]. Numbers of dead animals/total animals per group are given in parentheses

Previous reports demonstrated that blood transfusion-induced hemolysis caused excess mortality in a canine model of $S$. aureus pneumonia [5]. In the same model, administration of a haptoglobin concentrate improved shock, lung injury, and survival, suggesting that Hb-scavenging neutralized the adverse effects of CFHb [5]. With our model, we now provide direct evidence that purified $\mathrm{Hb}$ administered to reach clinically relevant plasma concentrations acts as a toxin during hemolysis, mimicking the adverse effect of intrinsic hemolysis. Our data collectively suggest that CFHb is a contributor to adverse sepsis outcomes and may provide a rationale for therapeutic haptoglobin supplementation as a strategy to improve clinical sepsis management.

Acknowledgements

Plasma-derived human haptoglobin (mixed phenotype) was provided by CSL-Behring, Bern, Switzerland. 


\section{Authors' contributions}

CAS designed the study, performed experiments, analyzed data, wrote the paper; VJ designed the study, performed experiments, analyzed data; TG analyzed plasma samples; DRS and AR designed the study; FV wrote the paper; DJS designed the study, analyzed data. All authors read and approved the final manuscript.

\section{Funding}

The study was supported by Innosuisse (Grant number 19300.1 PFSL-L) and the Swiss National Science Foundation (Grant number 310030_197823).

\section{Availability of data and materials}

Original data are available upon reasonable request from the corresponding author.

\section{Declarations}

Ethical approval and consent to participate

This animal study was approved by the Veterinary Office of the Kanton Zurich, Switzerland.

\section{Consent for publication}

Not applicable for this animal study.

\section{Competing interests}

The authors declare that they have no competing interests.

\section{Author details}

${ }^{1}$ Division of Internal Medicine, University and University Hospital Zurich, Raemistrasse 100, 8091 Zurich, Switzerland.

${ }^{2}$ Institute of Anesthesiology, University and University Hospital Zurich, Raemistrasse 100, 8091 Zurich, Switzerland.

${ }^{3}$ CSL Behring AG, Bern, Switzerland. ${ }^{4}$ Department of Medicine, Hospital Limmattal, Urdorferstrasse 100, 8952 Schlieren, Switzerland.

Received: 22 February 2021 Accepted: 13 April 2021

Published online: 03 May 2021

\section{References}

1. Buehler PW, Humar R, Schaer DJ (2020) Haptoglobin therapeutics and compartmentalization of cell-free hemoglobin toxicity. Trends Mol Med 26(7):683-697

2. Janz DR, Bastarache JA, Peterson JF, Sills G, Wickersham N, May AK et al (2013) Association between cell-free hemoglobin, acetaminophen, and mortality in patients with sepsis: an observational study. Crit Care Med 41:784-790

3. Janz DR, Bastarache JA, Sills G, Wickersham N, May AK, Bernard GR et al (2013) Association between haptoglobin, hemopexin and mortality in adults with sepsis. Crit Care. 17(6):R272

4. Adamzik M, Hamburger T, Petrat F, Peters J, de Groot H, Hartmann M (2012) Free hemoglobin concentration in severe sepsis: methods of measurement and prediction of outcome. Crit Care 16(4):R125

5. Remy KE, Cortés-Puch I, Solomon SB, Sun J, Pockros BM, Feng J et al (2018) Haptoglobin improves shock, lung injury, and survival in canine pneumonia. JCl Insight 3(18):e123013

6. Rudiger A, Jeger V, Arrigo M, Schaer CA, Hildenbrand FF, Arras M et al (2018) Heart rate elevations during early sepsis predict death in fluid-resuscitated rats with fecal peritonitis. Intensive Care Med Exp 6:28

7. Boretti FS, Buehler PW, Dgnillo F, Kluge K, Glaus T, Butt Ol et al (2009) Sequestration of extracellular hemoglobin within a haptoglobin complex decreases its hypertensive and oxidative effects in dogs and guinea pigs. J Clin Investig. 119:2271-2280

8. Deuel JW, Vallelian F, Schaer CA, Puglia M, Buehler PW, Schaer DJ (2015) Different target specificities of haptoglobin and hemopexin define a sequential protection system against vascular hemoglobin toxicity. Free Radic Biol Med 89:931-943

\section{Publisher's Note}

Springer Nature remains neutral with regard to jurisdictional claims in published maps and institutional affiliations. 